\title{
THERMAL AND MECHANICAL PROPERTIES OF P(MMA-co-BMA)/MWNTs NANOCOMPOSITES
}

\author{
Fang HUANG, ${ }^{\mathrm{a}}$ Fuquan GUO ${ }^{\mathrm{b},{ }^{*}}$ and Guoqin LIU ${ }^{\mathrm{a},{ }^{*}}$ \\ ${ }^{\mathrm{a} C}$ College of Material Science and Engineering, Henan University of Technology, Zhengzhou, 450001, China \\ ${ }^{\mathrm{b}}$ School of Materials Science and Engineering, Luoyang Institute of Science and Technology, Luoyang, 471023, China
}

P(MMA-co-BMA)/MWNTs (poly(methyl methacrylate-co-butyl methacrylate)/multi-walled carbon nanotubes) nanocomposites were synthesized. The thermal and mechanical properties of the nanocomposites were investigated. The results show that, the acid-treated MWNTs can be uniformly dispersed into P(MMA-co-BMA) matrix, and significantly improve its thermal stability and mechanical performance of P(MMA-co-BMA).

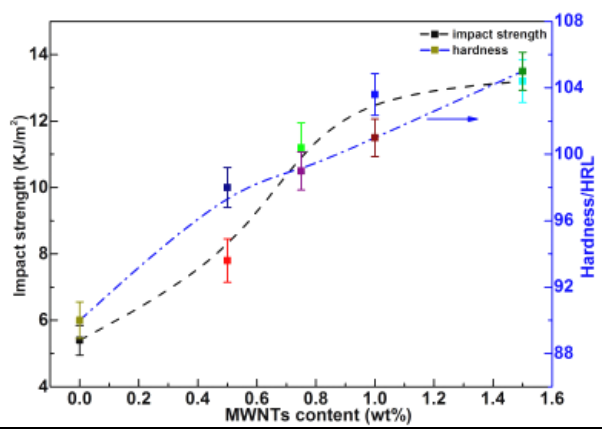

\section{INTRODUCTION}

Due to the performance enhancement obtained when a small amount of nano-sized particles is incorporated into a polymer matrix, polymer-based nanocomposites have been drawn more attention. ${ }^{1-5}$ The high surface area to volume ratio of nanoparticles can effectively enhance the interactions between nanofillers and polymers. Moreover, polymer-based nanocomposites are often produced using conventional polymer composites processing methods, making them extra valuable from a manufacturing point of view.

PMMA is widely used acrylate polymers with colorlessness and high light transmittance, anti-chemical corrosion resistance, easy handling and processing. From a cost point of view, PMMA is a better alternative to PC (polycarbonate) if a high strength quality is not required. On the other hand, the weaker thermal stability and mechanical properties usually restrict its wide application.
Thus, to enhance these properties, in the recent years, some researchers have incorporated inorganic nanoparticles (or nanophase materials) as filler into PMMA to overcome its drawbacks. Those fillers include EG (exfoliated graphite), graphene, $\mathrm{SiO}_{2}, \mathrm{CNTs}, \mathrm{TiO}_{2}, \mathrm{ZnO}, \mathrm{ZrO}_{2}, \mathrm{Al}$, calcium carbonate nanoparticles, clay, and so on. ${ }^{6-16}$

BMA is chosen as a copolymerized monomer because its homopolymer PBMA exhibits a low glass-transition temperature, which is very important, and is softer than PMMA because of PBMA containing $4 \mathrm{C}$ atoms in its chain; thus, it is generally used in copolymers to alleviate polymer brittleness. ${ }^{17}$ In this work, P(MMA-co-BMA) are prepared in the presence of MWNTs, i.e., $\mathrm{P}(\mathrm{MMA}-\mathrm{co-BMA}) / \mathrm{MWNT}$ nanocomposites. The inclusion of MWNTs into a polymer can improve its mechanical properties and thermal behaviour. The effects of MWNTs on the nanocomposites properties are researched.

\footnotetext{
*Corresponding author: guopaper0371@163.com (Prof. Guo), polymerpaper@163.com (Prof. Liu)
} 


\section{RESULTS AND DISCUSSION}

FTIR (Fourier transform infrared) spectra are used to characterize the functional groups of pristine MWNTs, acid-treated MWNTs, P(MMA-co-BMA) and $\mathrm{P}(\mathrm{MMA}-\mathrm{co}-\mathrm{BMA}) / 1.5 \mathrm{wt} \%$ MWNTs nanocomposites, as shown in Figure 1. The hexagonal structure of the pristine MWNTs is in appearance of peak at $1532 \mathrm{~cm}^{-1}$, indicating existence of carbon double bonding $(\mathrm{C}=\mathrm{C}) .{ }^{18}$ Decreasing of the $\mathrm{C}=\mathrm{C}$ absorbance indicates oxidation of carbon, which leads to obvious emergence of peak at $1723 \mathrm{~cm}^{-1}$ as carbonyl $(\mathrm{C}=\mathrm{O})$ of carboxyl $(\mathrm{COOH})$ group and demonstrates the carboxylation on acid-treated MWNTs surfaces. ${ }^{19,20}$ The treatment process of $\mathrm{HNO}_{3}$ causes the improvement of purity as well as partial oxidization of carbon. The number of functional groups increases after $\mathrm{HNO}_{3}$ oxidation. $\mathrm{HNO}_{3}$ attacks the $\mathrm{C}=\mathrm{C}$ in decreasing peak region at $1532 \mathrm{~cm}^{-1}$ and the hexagonal carbon at region $500-1000 \mathrm{~cm}^{-1}$. Reducing of the peak intensity shows the presence of large lumber of asymetrical hexagonal carbon. The sharp peak at $1646 \mathrm{~cm}^{-1}$ is the carbonyl of quinone type units along the side-walls of the nanotubes, which decreases after acid treatment. Those analyses show the $\mathrm{COOH}$ formation on the side-walls of the MWNTs. For P(MMA-co-BMA), due to the absence of $\mathrm{OH}$ group, there is no characteristic infrared absorption peak around $3400 \mathrm{~cm}^{-1} ; \mathrm{C}=\mathrm{O}$ and $\mathrm{C}-\mathrm{O}$ stretching vibrations appear at 1730 and $1153 \mathrm{~cm}^{-1}$, respectively. After the combination of P(MMA-co-BMA) and MWNTs, in P(MMA-co-BMA) $/ 1.5 \mathrm{wt} \%$ MWNTs FTIR spectra, it can be observed, there is a broad peak around $3492 \mathrm{~cm}^{-1}$ corresponding to $\mathrm{OH}$ vibration in comparison with $\mathrm{P}(\mathrm{MMA}-\mathrm{co-BMA})$ and acid-treated MWNTs; meanwhile, $\quad \mathrm{C}=\mathrm{O}$ stretching vibration of $\mathrm{P}(\mathrm{MMA}-\mathrm{co}-\mathrm{BMA}) / 1.5 \mathrm{wt} \%$ MWNTs shifts to a longer wavenumber of 1752 $\mathrm{cm}^{-1}$, which may result from the interactions between P(MMA-co-BMA) and MWNTs, namely forming hydrogen bonds.

The cryo-fractured surface morphology and MWNTs dispersion states in P(MMA-co-BMA) can be analyzed in SEM (Scanning electron microscopy). In fact, realizing the uniform dispersion of MWNTs is generally a difficult task as a result of their strong van der Waals forces leading to powerful tendency to gather and form aggregates. $^{21}$ After the ultrasonic and acid treatment, the dispersion of MWNTs is facilitated, as shown in Figure 2. Some MWNTs are pulled out with another end still insetting in polymer matrix similar to 'pinning effect'. The exposed ends of
MWNTs, due to high conductivity, appear as randomly distributed bright spots in the electric field. $^{22}$ Those situations mean that there exists interaction forces between MWNTs and polymer matrix, which can promote the efficient transmission of the load between them and significantly enhance the dynamic mechanical properties of polymer. ${ }^{23}$ By contrast, owing to MWNTs being pulled out from polymer matrix, they leave some holes on the fractured surface. No matter the bright ends or the holes are uniformly dispersed with few MWNTs aggregations. By $\mathrm{HNO}_{3}$ treatment, the surface of MWNTs is attached some $\mathrm{COOH}$ or $\mathrm{OH}$; they may be beneficial for increasing intermolecular forces or forming hydrogen bonds between the MWNTs and the polymer matrix, which improves the MWNTs dispersion, and decreases the severe MWNTs aggregation formation. Thus, in Figure 2, the even distribution of MWNTs can be clearly seen in P(MMA-co-BMA).

The cryo-fractured surface morphology and MWNTs dispersion states in P(MMA-co-BMA) can be analyzed in SEM (Scanning electron microscopy). In fact, realizing the uniform dispersion of MWNTs is generally a difficult task as a result of their strong van der Waals forces leading to powerful tendency to gather and form aggregates. $^{21}$ After the ultrasonic and acid treatment, the dispersion of MWNTs is facilitated, as shown in Figure 2. Some MWNTs are pulled out with another end still insetting in polymer matrix similar to 'pinning effect'. The exposed ends of MWNTs, due to high conductivity, appear as randomly distributed bright spots in the electric field. $^{22}$ Those situations mean that there exists interaction forces between MWNTs and polymer matrix, which can promote the efficient transmission of the load between them and significantly enhance the dynamic mechanical properties of polymer. ${ }^{23}$ By contrast, owing to MWNTs being pulled out from polymer matrix, they leave some holes on the fractured surface. No matter the bright ends or the holes are uniformly dispersed with few MWNTs aggregations. By $\mathrm{HNO}_{3}$ treatment, the surface of MWNTs is attached some $\mathrm{COOH}$ or $\mathrm{OH}$; they may be beneficial for increasing intermolecular forces or forming hydrogen bonds between the MWNTs and the polymer matrix, which improves the MWNTs dispersion, and decreases the severe MWNTs aggregation formation. Thus, in Figure 2, the even distribution of MWNTs can be clearly seen in P(MMA-co-BMA). 


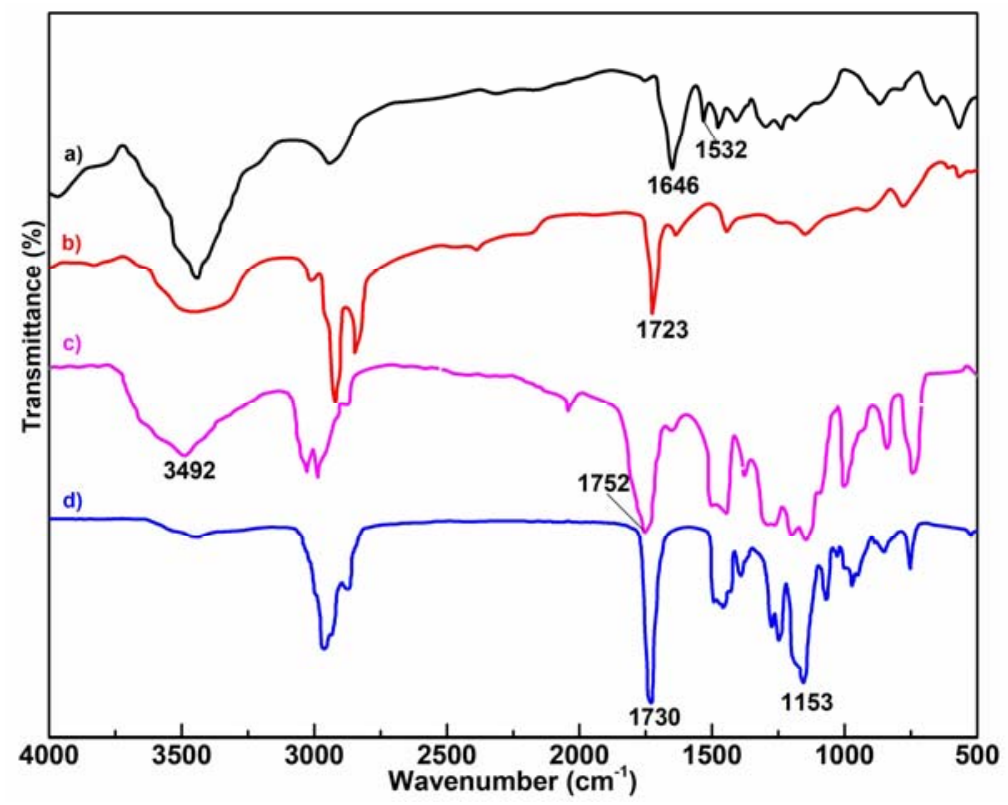

Fig. 1 - FTIR spectra of pristine MWNTs (a)), acid-treated MWNTs (b)), P(MMA-co-BMA)/1.5 wt\% MWNTs (c)) and P(MMA-co-BMA) (d)).
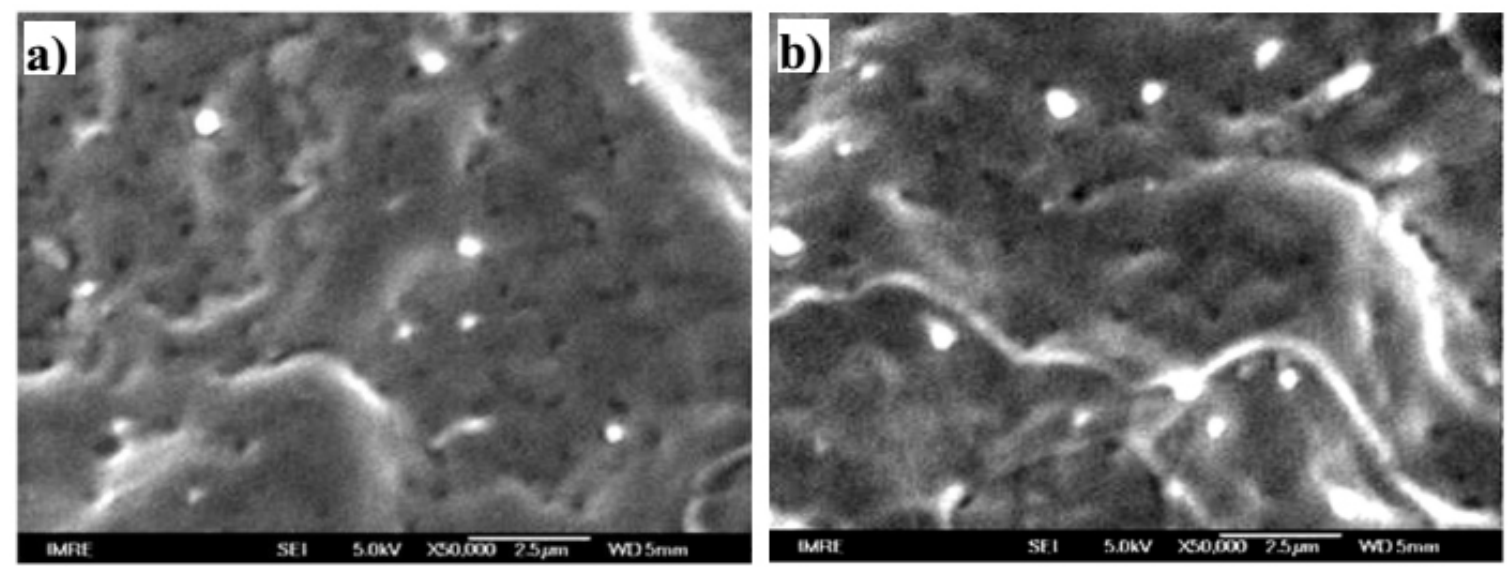

Fig. 2 - SEM of P(MMA-co-BMA)/MWNTs nanocomposites. a) $0.5 \mathrm{wt} \%$ MWNTs; b) $1.5 \mathrm{wt} \%$ MWNTs.

DMAs (Dynamic mechanical analyses) of P(MMA-co-BMA) and its nanocomposites with 0.5 , $0.75,1$ and $1.5 \mathrm{wt} \%$ of MWNTs are in Figure 3. The stiffness of the visco-elastic materials can be expressed by the storage modulus $\left(\mathrm{E}^{\prime}\right)$ and the energies stored are proportional to E'. At low temperatures, molecular motions are 'frozen', so that they can't resonate with oscillatory loads, and thus keep rigid. Polymer segments are restricted with no shape change. As the temperature rises, the macromolecular segments move more and more easily, and readily resonate with the load; although the macromolecules still remain firmly entangled each other, those slipping and disentanglement may partly happen. The increase in the nanocomposite' $E^{\prime}$ is clearly the contribution of MWNTs that the presence of MWNTs makes less free space for macromolecular vibration. The well-dispersed
MWNTs have an important influence on its surrounding polymeric matrix, play a role of physical crosslinking, limit the motion of macromolecular segments and basically alter polymeric thermal and mechanical properties. ${ }^{24,25}$

In Figure 3 a), E' of P(MMA-co-BMA) is 0.419 $\mathrm{GPa}$ at $20{ }^{\circ} \mathrm{C}$; for the nanocomposites with $0.5,0.75$, 1.0 and $1.5 \mathrm{wt} \%$ of MWNTs, the corresponding values of $E^{\prime}$ are $0.493,0.546,0.558$ and $0.619 \mathrm{GPa}$, respectively; with respect to that of $\mathrm{P}(\mathrm{MMA}-\mathrm{co}-$ BMA), $E^{\prime}$ of the nanocomposites shows a certain increase, a rise of at least $21.4 \%$. At $90{ }^{\circ} \mathrm{C}$, those are $0.132,0.249,0.281,0.318$ and $0.358 \mathrm{GPa}$; $\mathrm{E}^{\prime}$ of the nanocomposites is higher at least more than 1.7 -fold with respect to P(MMA-co-BMA). When MWNTs are incorporated into polymers, it seems that MWNTs play a critical role in the effective immobilization of polymer chains motion. So, P(MMA-co-BMA)/ 
MWNTs nanocomposites have higher E' values and it is no doubt, with MWNTs content increasing, the initial E' of the nanocomposites also raises.

$\mathrm{T}_{\mathrm{g}}$ (glass transition temperature) can obtain from the loss factor $(\operatorname{Tan} \delta)$ in DMA and is taken from the temperatrue corresponding to the maximum $\operatorname{Tan} \delta$. Figure $3 \mathrm{~b}$ ) shows $\operatorname{Tan} \delta$ as a function of temperature. Due to their smaller size, larger surface areas and attached - $\mathrm{COOH}$ groups, MWNTs can intensively adsorb macromolecules and restrict their movements. Thus, with MWNTs content increasing, $T_{g}$ of P(MMA-co-BMA)/MWNTs nanocomposites increases. Taking $\mathrm{T}_{\mathrm{g}}$ of $\mathrm{P}(\mathrm{MMA}-\mathrm{co-BMA})$ as a contrast, addition of MWNTs increases the $T_{g}$ of the nanocomposites by at least $10{ }^{\circ} \mathrm{C}$. The increase in $\mathrm{T}_{\mathrm{g}}$ means that MWNTs well disperse in P(MMA-coBMA), and the bigger interfacial areas of MWNTs alter polymer chain mobility throughout the nanocomposites. The interactions between polymer matrix and MWNTs reduce the polymer chain mobility and make an increase in $\mathrm{T}_{\mathrm{g}}$ and modulus.

DSC (Differential scanning calorimetry) is applied to research the glass transition of polymers. The thermograms of P(MMA-co-BMA) and its nanocomposites are shown in Figure $4 \mathrm{a}$ ). The $\mathrm{T}_{\mathrm{g}}$ of $\mathrm{P}$ (MMA-co-BMA) is found at $c a .104{ }^{\circ} \mathrm{C}$, those of the nanocomposites are 107,110, 112 and 115 ${ }^{\circ} \mathrm{C}$. The higher $\mathrm{T}_{\mathrm{g}}$ of the nanocomposites is resulted from the homogeneous dispersion of rigid MWNTs. MWNTs can limit the movement of polymer chains segments and raise $T_{g}$ of the nanocomposites. Although $T_{g}$ tested by DSC differs from that of DMA, their results display similar trends.

TGA (Thermogravimetric analysis) evaluates the thermal stabilities of MWNTs, P(MMA-coBMA) and their nanocomposites. Figure $4 \mathrm{~b}$ ) shows that $\mathrm{T}_{\mathrm{d}}(5 \%$ weight loss temperature) of $\mathrm{P}$ (MMA-co-BMA) is at least $c a .28 \mathrm{C}^{\circ}$ lower than that of the nanocomposites. MWNTs can hinder the thermal degradation of the nanocomposites. The uniformly dispersed MWNTs guard against the release of thermally decomposed small gaseous molecules and increase $T_{d}$ of the nanocomposites. On the other hand, at the same temperature, the more the MWNTs contents, the more the residual weight of the nanocomposites. At $386{ }^{\circ} \mathrm{C}$, the nanocomposites weight loss is at least $36 \%$ and at most 79\%; however, for P(MMA-co- BMA), it is around $86 \%$. These phenomena prove that MWNTs effectively increase the heat resistance of $\mathrm{P}$ (MMA-co-BMA).

Tensile tests are performed on P(MMA-coBMA) and its nanocomposites. Figure 5 a) is the stress-strain $(\sigma-\varepsilon)$ curves for P(MMA-co-BMA) and its nanocomposites with various MWNTs contents. P(MMA-co-BMA) shows few elastic behavior. Prior to tensile fracture, it deforms just a little and its strain-to-break $\left(\varepsilon_{\mathrm{B}}\right)$ is only $4.72 \%$. The lower $\varepsilon_{\mathrm{B}}$ is resulted from P(MMA-co-BMA) cross-linking networks structure. The MWNTs can cause distinct changes in its stress-strain curves. Initially, the yield point raises to about $\varepsilon_{B}=6.12 \%$ for P(MMA-co-BMA) $/ 0.5$ wt $\%$ MWNTs nanocomposites. With the further increase of MWNTs content, the $\varepsilon_{B}$ of P(MMA-co-BMA)/1.5 wt $\%$ MWNTs nanocomposites is $11.2 \%$. Generally speaking, most polymer-based nanocomposites exhibit brittleness when added even a small content of CNTs. But, in this study, the $\varepsilon_{B}$ of $\mathrm{P}(\mathrm{MMA}-\mathrm{co}-\mathrm{BMA}) / \mathrm{MWNTs}$ nanocomposites increases, meaning that the toughness of nanocomposites is enhanced, which may be because, with increasing the MWNTs loading, the PEG quantity incorporated into the nanocomposite also increases and the increasing amount of PEG will endow the nanocomposites with more flexibility.
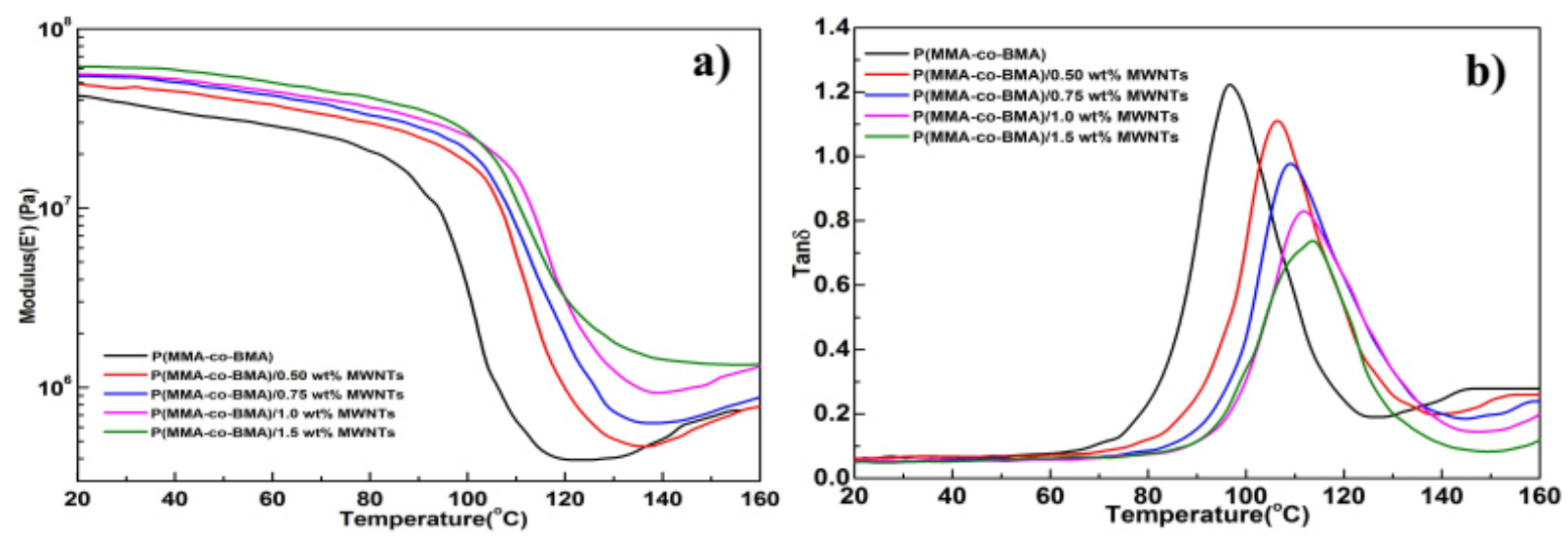

Fig. 3 - Dynamic mechanical results for P(MMA-co-BMA) and its nanocomposites. a) E' and b) Tan $\delta$. 

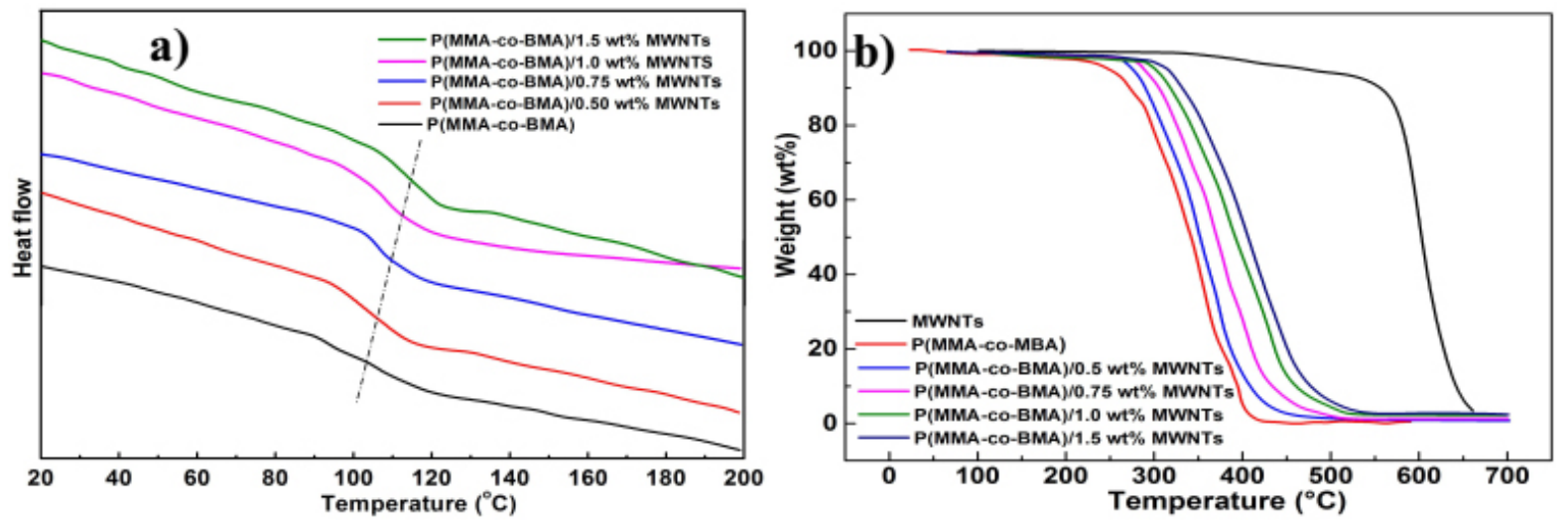

Fig. 4 - DSC (a)) and TGA (b)) of P(MMA-co-BMA) and its nanocomposites.
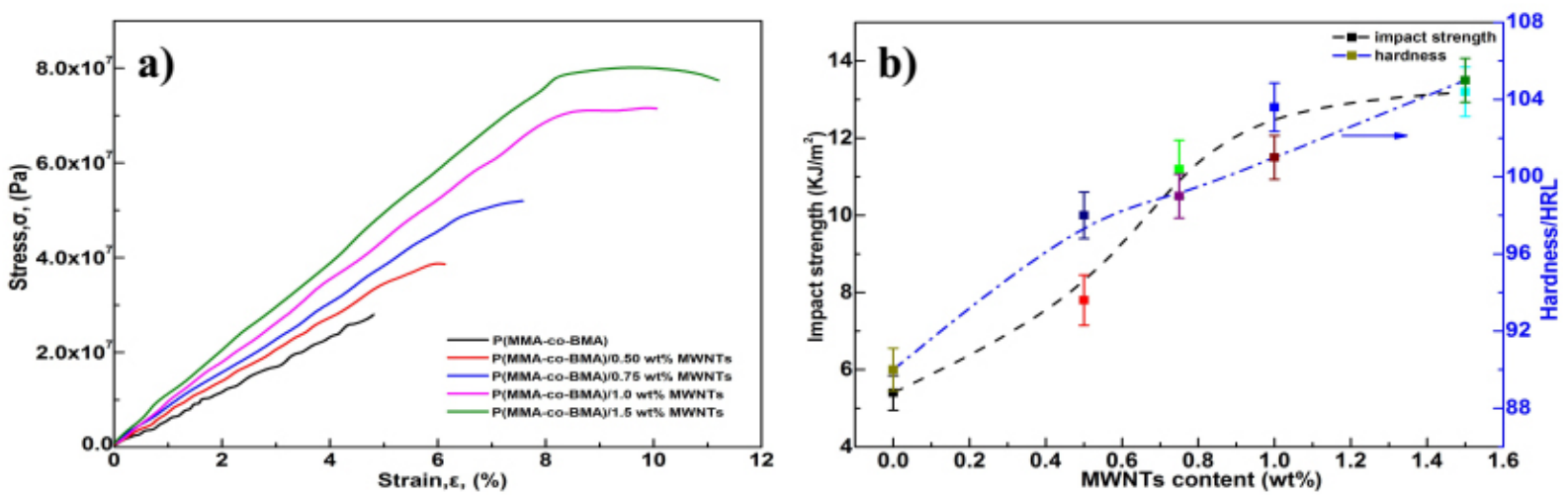

Fig. 5 - Stress-strain curves (a), Hardness and Izod impact strength, (b) of P(MMA-co-BMA) and its nanocomposites.

Figure $5 \mathrm{~b}$ ) shows the microhardness and Izod impact strength of P(MMA-co-BMA) and its nanocomposites. The hardness of nanocomposite at $0.5 \mathrm{wt} \%$ MWNTs increases from $90 \mathrm{HRL}$ for P(MMA-co-BMA) to $98 \mathrm{HRL}$. The hardness of nanocomposite at $1.5 \mathrm{wt} \%$ MWNTs increases to 105 HRL. More importantly, even low MWNTs contents, the hardness still apparently increases, as shown in Figure $5 \mathrm{~b}$ ), indicating a uniform dispersion of MWNTs in P(MMA-co-BMA). The increase in microhardness may be attributed to higher microhardness of MWNTs compared with P(MMA-co-BMA). Izod impact strength of P(MMA-co-BMA) and its nanocomposites also dispalys in Figurea $5 \mathrm{~b}$ ). Obviously, the impact strength of the nanocomposites increases with increasing of MWNTs contents. In comparsion with $\mathrm{P}(\mathrm{MMA}-\mathrm{co-BMA})$, the impact strength of the nanocomposites has increased by at least $44 \%$, which can be attributed to a uniform dispersion of MWNTs. The rigid MWNTs act as physical cross-linkers, thus improve the impact strength of the nanocomposites. Because the physical crosslinking is reversible, its impact strength also simultaneously increases as the stiffness of the nanocomposite increases.

\section{EXPERIMENTAL}

MWNTs are bought from Shenzhen Nanotech Port, with a purity of above $96 \%$, average length of microns, and surface area of $4.26 \mathrm{~m}^{2} \cdot \mathrm{g}^{-1}$. MMA, BMA, and AIBN (2, 2'-azobis(isobutyronitrile)) are purchased from Chengdu Reagent Factory (China). In order to remove the polymerization inhibitors, MMA and BMA are purified seperately by decompressing distillation. AIBN is refined by recrystallization in ethanol solution. MBAA (N,N'-methylenebis(acrylamide), Aldrich) and PEG (poly(ethylene glycol), Aldrich, $\mathrm{M}_{\mathrm{w}}=10000$ ) are used without further treatment and chosen as a cross-linker, a dispersant and a plasticizer, separately.

MWNTs are immersed in $3 \mathrm{~mol} \cdot \mathrm{l}^{-1} \mathrm{HNO}_{3}$ and refluxed for $6 \mathrm{hr}$. Then, MWNTs are rinsed in distilled water till the $\mathrm{pH}$ of the flushing fluid is close to 7, and filtered. At last, the acid-treated MWNTs dry in a vacuum oven. BMA ( $6 \mathrm{wt} \%$ of the total weight of the monomers (TWM)) and MMA (94 wt $\%$ of TWM), PEG (the weight ratio of MWNTs and PEG being $1: 1)$, AIBN ( $0.1 \mathrm{wt} \%$ of TWM ), MBAA (3 wt $\%$ of TWM) and the acid-treated MWNTs (the addition amount of MWNTs is $0.5,0.75,1.0$, and $1.5 \mathrm{wt} \%$ of TWM, respectively), are uniformly mixed and ultrasonicated for $0.5 \mathrm{hr}$. Subsequently, $\mathrm{N}_{2}$ is fed into the mixture to remove $\mathrm{O}_{2}$. The mixture is quickly heated to $60{ }^{\circ} \mathrm{C}$ with uniform stirring for $10 \mathrm{~min}$, and then cools to $55^{\circ} \mathrm{C}$, and proceeds to polymerizing for $24 \mathrm{hr}$. The obtained P(MMA-co-BMA)/MWNTs nanocomposites are dried under vacuum at $70{ }^{\circ} \mathrm{C}$ for $24 \mathrm{hr}$.

FTIR (Nicolet 200SXV) and SEM (JSM-6700F) are applied for the characterization of MWNTs and the 
nanocomposites. DMA (Du Pont 983 DMA) is done at a $0.1 \mathrm{~mm}$ oscillation amplitude and a $1 \mathrm{~Hz}$ frequency. DSC (Du Pont 9900) is used to measure $\mathrm{T}_{\mathrm{g}}$ of polymer over a temperature scope between 20 and $200{ }^{\circ} \mathrm{C}$ at a $10{ }^{\circ} \mathrm{C} \cdot \mathrm{min}^{-1}$ heating rate. $\mathrm{T}_{\mathrm{d}}$ is tested by TGA (Perkin-Elmer) under air at a heating rate of $10{ }^{\circ} \mathrm{C} \cdot \mathrm{min}^{-1}$. The universal testing machine (WDW-50) is applied to the tensile test of the sample. The hardness (in HRL unit) test is performed using a Rockwell hardness tester, and conducts at a dwell load of $5 \mathrm{~N}$ and dwell time of $10 \mathrm{sec}$. The notched Izod impact strength of the composites is tested using XJ-40A pendulum apparatus.

\section{CONCLUSIONS}

P(MMA-co-BMA)/MWNTs nanocomposites are prepared with various MWNTs contents. The MWNTs are uniformly dispersed in P(MMA-coBMA). DSC and TGA tests show that the incorporation of MWNTs into P(MMA-co-BMA) clearly increases its $\mathrm{T}_{\mathrm{g}}$ over $10{ }^{\circ} \mathrm{C}$ and improves its heat resistance. The nanocomposites have an increment in elastic modulus of at least $21.4 \%$ at $20{ }^{\circ} \mathrm{C}$, and are higher at least more than 1.7 -fold at $90{ }^{\circ} \mathrm{C}$. The $\varepsilon_{\mathrm{B}}$ of the nanocomposites increases with MWNTs contents increasing, which means the nanocomposites become more flexible as more nanotubes are added; those are probably due to the plasticizing effect of the increase in PEG content; in comparison to the P(MMA-co-BMA), the hardness and impact strength of the nanocomposites increase at least 2 times and 44\%, respectively.

Acknowledgments. Financial support from the Science and Technology Project of Henan Province (No. 172102210033) and Key Scientific Research Projects of Universities in Henan Province (No. 17A530008).

\section{REFERENCES}

1. T. Gatti, N. Vicentini, M. Mba and E. Menna, Eur. J. Org. Chem., 2016, 6, 1071-1090.

2. T. V. Prateek and R. K. Gupta, Chem. Rev., 2016, 116, 4260-4317.
3. G. Zhao, X. Huang, Z. Tang, Q. Huang, F. Niu and X. Wang, Polym. Chem., 2018, 9, 3562-3582.

4. N. Horny, Y. Kanake, M. Chirtoc and L. Tighzert, Polym. Degrad. Stab., 2016, 127, 105-112.

5. S. Geng, K. Yao, Q. Zhou and K. Oksman, Biomacromolecules, 2018, 19, 4075-4083.

6. M. J. Roshan, A. Jeevika, A. Bhattacharyya and D. R. Shankaran, Mater. Res. Bull., 2018, 105, 133-141.

7. J. M. Thomassin, M. Trifkovic, W. Alkarmo, C. Detrembleur, C. Jérôme and C. Macosko, Macromolecules, 2014, 47, 2149-2155

8. D. Fang, C. Zhou, G. Liu, G. Luo, P. Gong, Q. Yang, Y. Niu and G. Li, Polymer, 2018, 148, 68-78.

9. E. E. Totu, A. C. Nechifor, G. Nechifor, H. Y. Aboul-Enein and C. M. Cristache, J. Dent., 2017, 59, 68-77.

10. M. Cierech, A. Kolenda, A. M. Grudniak, J. Wojnarowicz, B. Woźniak, M. Gołaś, E. Swoboda-Kopeć, W. Łojkowski and E. Mierzwińska-Nastalska, Int. J. Pharm., 2016, 510, 323-335.

11. S. Hammani, A. Barhoum and M. Bechelany, J. Mater. Sci., 2018, 53, 1911-1921.

12. M. A. Reyes-Acosta, A. M. Torres-Huerta, M. A. Dominguez-Crespo, A. I. Flores-Vela, H. J. Dorantes-Rosales and E. Ramírez-Meneses, J. Alloys Compd. 2015, 64, S150-S158

13. S. K. Sharma, K. Sudarshan, M. Sahu and P. K. Pujari, RSC Adv., 2016, 6, 67997-68004.

14. A. Chatterjee and S. Mishra, Macromol. Res., 2013, 21, 474-483.

15. Y. Zare and H. Garmabi, Appl. Clay Sci., 2015, 105, 66-70.

16. E. Bashtani, A. Amiri and M. Baghayeri, Microchim. Acta, 2018, 185, 14.

17. X. Qiu, G. Song, X. Chu, X. Li and G. Tang, Sol. Energy, 2013, 91, 212-220.

18. M. V. Naseh, A. A. Khodadadi, Y. Mortazavi, O. A. Sahraei, F. Pourfayaz and S. M. Sedghi, World Acad. Sci. Eng. Technol., 2009, 49, 177-179.

19. S. Chen, W. Shen, G. Wu, D. Chen and M. Jiang, Chem. Phys. Lett., 2005, 402, 312-317.

20. S. Y. Lee and S. J. Park, Bull. Korean Chem. Soc., 2010, 31, 1596-1600.

21. P. M. Ajayan, L. S. Schadler, C. Giannaris and A. Rubio, Adv. Mater., 2000, 12, 750-753.

22. D. Chen, M. Wang, W. D. Zhang and T. Liu, J. Appl. Polym. Sci., 2009, 113, 644-650.

23. G. X. Chen, H. S. Kim, B. H. Park and J. S. Yoon, Polymer, 2006, 47, 4760-4767.

24. S. T. Kim, H. J. Choi and S. M. Hong, Colloid Polym. Sci., 2007, 285, 593-598.

25. Y. Zhao, Z. Qiu and W. Yang, J. Phys. Chem. B, 2008, 112, 16461-16468. 